\title{
A DIALÉTICA DO SER-NADA-DEVIR: DESDOBRAMENTOS DA CIÊNCIA DA LÓGICA DE HEGEL
}

\author{
The Dialetics of Being-Nothing-Becoming: Hegel's Science of Logic Developments
}

Lauro Ericksen*

Resumo: O trabalho tem o escopo geral de mostrar os aspectos mais relevantes dos desdobramentos filosóficos contidos na "Ciência da Lógica" de Hegel, enfocando-se nos elementos dialéticos da sistemática do ser-nadadevir. Seus objetivos específicos são: identificar os conceitos de cada unidade lógica, descrevendo suas funções no entendimento onto-metafísico da realidade; expor a unidade e a oposição contidas nos conceitos mínimos de ser e de nada; e escrutinar as possibilidades do pensamento sobre a realidade extraídas das formas categoriais da dialética do ser, do nada e do devir. Metodologicamente, segue-se a assertiva hegeliana da busca pelo puro ser, como uma noção mínima de uma categoria lógica que possibilita a assunção de uma nova premissa básica de assentamento da filosofia em sua conceituação lógica. Como resultado, tem-se que a verdade desse sistema dialético pode ser compreendida como o trespasse lógico entre o ser e o nada em direção ao devir, a essência de qualquer posicionamento metafísico. Conclui-se que as contribuições de Hegel para a filosofia e para a construção de uma ciência da lógica moderna são bastante coesas e sólidas, de modo que estabelecem uma base importante para um novo implemento filosófico baseado na compreensão lógica da realidade metafísica.

Palavras-chave: Metafísica, Lógica, Ser, Nada, Devir.

\begin{abstract}
This paper has the general intent to show the major aspects of metaphysical comprehension of Hegel's Science of Logic, focusing on the dialectical aspects of being, nothing and becoming. Its specific objectives are: identify the concept of each logical unity, describing it function of the onto-metaphysical understanding of reality; expose the unified yet opposed concept of being and nothing; and scrutinize the possibilities of the thinking extracted by the dialectical form of categories of being, nothing and becoming. Methodologically, the paper follows the Hegel's assertive of the search of the pure being, as a minimal notion of a logical category that can be able to state the basic premise of a new logical and philosophical assumption. As a result the truth of this dialectical system can be comprehended as the logical trespass between the being and the nothing towards the becoming, the essence of any metaphysical statement. It concludes that the Hegel's contribution is somewhat very cohesive and solid to the modern thinking and establishes the basis for a new philosophical implement based on logical comprehension of reality.
\end{abstract}

Keywords: Metaphysics, Logic, Being, Nothing, Becoming.

\footnotetext{
* Doutorando em Filosofia na Universidade Federal do Rio Grande do Norte (UFRN).

E-mail: lauroericksen@yahoo.com.br. Telefone: (84) 98868-8436.
}

\begin{tabular}{|c|c|l|l|l|l|}
\hline intuitio & $\begin{array}{c}\text { ISSN } \\
1983-4012\end{array}$ & Porto Alegre & Vol.10 $-\mathrm{N}^{\mathrm{o} .1}$ & $\begin{array}{l}\text { Julho } \\
2017\end{array}$ & p. 47-67 \\
\hline
\end{tabular}




\section{Introdução}

No estudo da filosofia e da metafísica, um dos pontos de maior destaque dentro da sua história é a passagem da época da filosofia moderna para a filosofia contemporânea. Usualmente, se aponta como ponto crítico dessa passagem os primeiros escritos de Georg Wilhelm Friedrich Hegel. Esses escritos são importantes porque, de algum modo, implementam e criticam o entendimento formulado por Immanuel Kant no final do século XVII e de seus seguidores (Jacobi, Reinhold, Fichte, dentre outros). A importância desse contexto de crise da metafísica (no século XIX) é destacada nos escritos hegelianos, em especial no seu tratamento dispensado à ciência da lógica, que, em última instância, é uma reformulação metafísica da compreensão crítica transcendental kantiana.

O tema central do trabalho em tela será analisar e perscrutar algumas das ideias empreendidas por Hegel no sentido de se opor ao estado de dominação de sua época. O panorama filosófico de seu tempo apontava para a derrocada e o declínio da Metafísica. No início do século XIX o positivismo estava em alta, e, por consequência, os estudos cientificistas dominavam o cenário filosófico deste período.

Hegel, todavia, não via com bons olhos essa expansão do conhecimento calcado apenas na experiência para a explicação filosófica das estruturas do pensamento, e da (anti) metafísica de um modo geral. Essa situação de despojo do conhecimento metafísico é que ficou conhecida como o paradoxo de um povo culto sem metafísica. Isso porque os estudiosos da época se focavam em extrair apenas da experiência todas as estruturas elementares do conhecimento, enquanto que a rejeição da metafísica era patente, principalmente, por considerarem que esse ramo da filosofia ainda possuía muitos elementos mitológicos, algo que o descurava da capacidade de apresentar uma explicação racional da realidade.

O problema para Hegel estava posto, como enfrentar o levante cientificista e anti-metafísico do início do século XIX e ainda ter que superar os escritos kantianos e suas interpretações decorrentes. Em síntese, dentre outros óbices intelectuais: como superar o argumento transcendental kantiano - muito embora seja de grande monta prover a ressalva de que a dissonância entre Kant e Hegel não era total, como bem aponta Frederik Beiser ${ }^{1}$. Haja vista que ambos concordavam que o problema da metafísica pretérita era seu dogmatismo, e o seu completo falhanço em investigar os poderes e limites da razão -, afinal, apelar para uma intuição intelectual é algo fortemente dogmático. Essa não seria uma tarefa fácil, afinal, o escopo primordial de Hegel era recolocar a metafísica no centro dos estudos filosóficos da sua época. Essa tarefa foi iniciada com a Fenomenologia do Espírito, todavia, no trabalho em comento, o foco principal da análise será outra obra sua denominada de Ciência da Lógica (do original em alemão: Wissenschaft der Logik) que teve sua primeira publicação em 1812.

${ }^{1}$ BEISER, F. Hegel. New York: Routledge, 2005, p. 156.

\begin{tabular}{|c|c|c|c|c|c|}
\hline intuitio & $\begin{array}{c}\text { ISSN } \\
1983-4012\end{array}$ & Porto Alegre & Vol.10 $-\mathrm{N}^{\mathrm{o}} .1$ & $\begin{array}{l}\text { Julho } \\
2017\end{array}$ & p. $47-67$ \\
\hline
\end{tabular}


$\mathrm{Na}$ supracitada obra, $\mathrm{Hegel}^{2}$ tenta encontrar uma fundamentação última e definitiva para que o problema cético levantado e apregoado por alguns filósofos predecessores fosse de vez espargido do cenário filosófico. Ou seja, ele necessitava formular uma fundamentação que pudesse ser suficiente para que nela a metafísica se assentasse e suas bases conceituais e sistemáticas fossem definitivas, válidas universalmente para seus propósitos. Essa, contudo, não era uma tarefa fácil. Observando alguns pontos da história da filosofia, Hegel percebeu que o único ramo que passou, desde os gregos (especificamente, desde Aristóteles), o desenvolvimento temporal sem mudanças significativas foi a lógica. Desde muito tempo as definições de realidade e de formalismo foram apartadas para que os regramentos formais constituíssem a sua base.

A lógica, portanto, por ser o estudo do lógos por excelência, e por demonstrar a capacidade de fornecer as estruturas fundamentais do pensamento, forneceria o terreno ideal para o desenvolvimento das ideias hegelianas. Campo esse que, indubitavelmente necessitaria de algumas mudanças intrínsecas na sua forma de congregar a realidade ao seu formalismo, pois, não seria mais admissível que houvesse tal forma de cisão entre as estruturas básicas do pensamento, totalmente teóricas, e as próprias expressões da realidade, que embora fossem ser tratadas de forma eminentemente teórica também, deveria ter uma concentração correspondente ao mesmo conhecimento que o cientificismo da época apregoava ter. Ou seja, as conjecturações da realidade definidas pela "nova lógica" deveriam ter um fundamento ontológicometafísico, de maneira que, a verdade nela contida não fosse apenas uma assertiva de condições de validade de seus enunciados ${ }^{3}$. Isso ocorre porque $\mathrm{Hegel}^{4}$ mantém que os conteúdos determinam as formas das categorias tanto quanto as suas próprias validações lógicas.

Até o momento de Hegel, a lógica tinha se fundado nessa dicotomia de verdade e certeza, a qual também, indubitavelmente, se desdobra na dicotomia observada entre o sujeito e o objeto. Isto é, era totalmente inapropriado que a lógica fizesse a abstração de qualquer conteúdo, uma vez que isso a conspurcaria seu elemento formalista, algo que se prezou por manter intacto desde os primórdios da lógica aristotélica. Para adentrar na sua doutrina do ser (e mais especificamente na dialética do ser, nada e devir), Hegel ainda tem que discutir pormenorizadamente, sob o viés metodológico, qual é (ou qual deveria ser) o começo da ciência. Afinal, a ciência da lógica deve se assentar sobre uma premissa básica que seja totalmente independente de qualquer formulação pretérita que tente identificar a verdade como adequação e que finde por recair nas dicotomias previamente enunciadas.

\footnotetext{
${ }^{2}$ HEGEL, G. W. F. Science of Logic. Tradução de W. H. Johnston e L. G. Struthers. London: George Allen \& Unwin, 1951, p.33.

${ }^{3}$ MARCUSE, H. Reason and Revolution: Hegel and The Rise of Social Theory. New York: Routledge, 1986, p.121.

${ }^{4}$ HEGEL, G. W. F. Science of Logic. Tradução de W. H. Johnston e L. G. Struthers. London: George Allen \& Unwin, 1951, p.35.
}

\begin{tabular}{|c|c|l|l|l|l|}
\hline intuitio & $\begin{array}{c}\text { ISSN } \\
1983-4012\end{array}$ & Porto Alegre & Vol.10- No.1 & $\begin{array}{l}\text { Julho } \\
2017\end{array}$ & p. $47-67$ \\
\hline
\end{tabular}


A lógica, nesse sentido, deve ser compreendida como a ciência pura, como bem fala o próprio Hegel $^{5}$, ela é o saber puro na amplitude total (ou espectro máximo de abrangência) do seu desenvolvimento. Seu começo, portanto, deve ser absoluto, não deve ser precedido por nada mais: um começo abstrato, seu começo é o puro ser ${ }^{6}$. Nesse horizonte, a lógica não se dispõe a clarificar todos os conceitos com os quais se opera, pois ela não se endereça para conceitos empíricos, tais como "cadeira" ou "mesa" (os quais podem variar amplamente sua definição em função da linguística local empregada), nem ela lida com conceitos que se aplicam especificamente à natureza (como o espaço e tempo) ou à história (como o Estado ou a sociedade).

Os enquadramentos lógicos impelem o exame das categorias gerais mais básicas com as quais se pensa, como o "ser", "realidade", "algo", "limite", "forma", "conteúdo" e "causa" - conceitos através dos quais se pode formular um entendimento mínimo de qualquer coisa em geral ${ }^{7}$. Importante destacar que a lógica, nessa acepção posta, não serve para pensar todos os conceitos, de maneira generalizante (que vise a abarcar todas as coisas possíveis), ela serve para pensar os conceitos elementares, aqueles que possibilitarão pensar os demais conceitos. Assim, simplesmente asseverar que a lógica serve de fundamento para todos os conceitos é uma indicação pouco precisa e não totalmente correta, afinal, apenas indiretamente é que todos os conceitos poderão ser pensados a partir da lógica, tal qual fundada na exposição por ora desenvolvida. O elemento principal desta fundamentação da lógica é que ela depende de um puro pensar, esse puro pensar, por seu turno, está diretamente ligado à questão do puro ser. É sobre essa premissa básica que se estatui a lógica da ciência tal como pensada por Hegel e este também o ponto de início do trabalho em tela.

Estruturalmente, o presente estudo se dividirá em outras três partes: a primeira observará como se é possível que o puro ser seja o constitutivo dessa nova forma de pensar lógica, como ele é o começo absoluto desse segmento; a segunda parte perscrutará os primeiros delineamentos acerca do ser, do nada e, posteriormente do devir; a terceira e última parte ficará encarregada de traçar os pormenores da dialética envolvida nesse processo, compreendendo a unidade ontológico-metafísica dessa relação entre ser e nada.

\section{A Questão da Categorização: Mediação e Imediação, Ser e Nada, Identidade e Diferença no Puro Ser}

O escopo fundamental de Hegel, tal como brevemente referido anteriormente, é dar um novo tratamento à lógica, fazendo com que ela seja o alicerce primeiro da filosofia. Para tanto, ela deve operar

\footnotetext{
${ }^{5}$ HEGEL, G. W. F. Science of Logic. Tradução de W. H. Johnston e L. G. Struthers. London: George Allen \& Unwin, 1951, p.15.

${ }^{6}$ SCHLITT, D. M. Hegel's Trinitarian Claim: A Critical Reflection. Leiden: E. J. Brill, 1984, p.16.

${ }^{7}$ HOULGATE, S. The Opening of Hegel's Logic: From Being to Infinity. West Lafayette: Purdue University Press, 2006, p.11.
}

\begin{tabular}{|c|c|c|c|c|c|}
\hline intuitio & $\begin{array}{c}\text { ISSN } \\
1983-4012\end{array}$ & Porto Alegre & Vol.10 $-\mathrm{N}^{\circ} .1$ & $\begin{array}{l}\text { Julho } \\
2017\end{array}$ & p. $47-67$ \\
\hline
\end{tabular}


de uma maneira totalmente distinta das outras ciências, sejam elas ciências da natureza (algo mais patente, já que o intuito paralelo desse intento é promover uma clara refutação do argumento cético de sua época) ou ciências matemáticas (de modo que ele não coaduna o método da lógica ao método analítico dessas ciências). Seu princípio se estatui de maneira a açambarcar o preceito de que tudo possa dele derivar, esse princípio, repise-se, é o próprio lógos.

A lógica necessita de um sistema formal que seja o desenho prévio do seu horizonte estrutural como sendo uma lógica das essências, e não mais uma lógica do conceito ou das ideias ${ }^{8}-$ se assim o fosse, não haveria nenhuma implementação significativa no sistema lógica a ser feita por Hegel, afinal, o sistema permaneceria a ser apenas um retrato "atualizado" do sistema colocado por Aristóteles há tempos - (dizer que a lógica hegeliana é essencialista de forma alguma vem a espargir de seus desdobramentos a influência dos conceitos ou das ideias, apenas a foca na sua "representação da realidade essencial"). Edgardo Albizu" bem explana o porquê dessa denominação de "lógica das essências". Segundo ele, "a lógica das essências é o momento de estruturação das significâncias".

A saber, a lógica é o momento em que o puro pensar, que equivale ao puro saber, assume o seu poder configurador, haja vista que, mesmo sendo imediata ao apresentar-se como puro ser ${ }^{10}$, nega essa imediatidade e entra em mediação consigo mesmo. Desta maneira, há de se pontuar porque o puro ser é imediato e porque também assume o caráter de mediação intrínseca tal como apresentado - algo que desvencilha a lógica hegeliana de qualquer ponderação formadora ou estruturante da experiência humana $^{11}$. O puro ser é a denominação mais geral que pode ser atribuída, ela dotada de uma vacuidade patente.

Aquilo que simplesmente é, por não possuir nenhuma determinação, nada é (esse ponto de equivalência entre o ser e o nada será mais bem explanado no próximo ponto deste trabalho). O começo da ciência contém, portanto, tanto o ser quanto o nada, de maneira indissoluvelmente agregada. É uma unidade de ser e nada, ou seja, é um não ser que é e um nada que é, esta é uma unidade indiferenciada que, repise-se, contém de forma imediata o ser e o nada. O que importa notar, é que o ser é imediato justamente por não depender de nenhum outro mecanismo que o determine. Não existe nenhuma outra estrutura do pensamento, seja ela formal ou não, que possa delineá-lo, isto é, que sirva instrumentalmente para a sua apresentação. Até porque o pensamento puro é a identidade entre o puro ser e o puro pensar - Edgardo Albizu $^{12}$ refere-se a essa identidade de ser = pensar como sendo um verdadeiro axioma da metafísica

\footnotetext{
${ }^{8}$ BUTLER, C. Hegel's Logic: Between Dialectic and History. Chicago: Northwestern University Press, 1996, p.12.

${ }^{9}$ ALBIZU, E. Hegel, Filósofo Del Presente. Buenos Aires: Almagesto, 2000, p.198.

${ }^{10} \mathrm{O}$ puro saber e o puro ser são conceitos, de maneira que contém em si a diferença de seus momentos, seja imediatamente ou mediatamente, eles podem ser, portanto, dissolvidos contraditoriamente no interior do próprio conceito.

${ }^{11}$ HOFFMAN, P. Doubt, Time, Violence. Chicago: The University of Chicago Press, 1989, p.73.

${ }^{12}$ ALBIZU, E. Hegel, Filósofo Del Presente. Buenos Aires: Almagesto, 2000, p.104.
}

\begin{tabular}{|c|c|c|c|c|c|}
\hline intuitio & $\begin{array}{c}\text { ISSN } \\
1983-4012\end{array}$ & Porto Alegre & Vol.10 $-\mathrm{N}^{\circ} .1$ & $\begin{array}{l}\text { Julho } \\
2017\end{array}$ & p. 47-67 \\
\hline
\end{tabular}


hegeliana, de modo que a sua vigência afigura-se evidente dentro do seu sistema lógico-ontológico -, outrossim, o pensar puro é o puro saber, pois apenas esse substrato teórico possibilita que se possa pensar qualquer outra coisa ulteriormente sem que se fique atrelado à dicotomia externa do sujeito-objeto. Assim sendo, o puro ser é imediato (e original), não existe nada a determiná-lo que possa se inserir no campo da transposição entre ele e a realidade, embora que, a partir dessa assertiva, não se possa compreender que existam "dois planos", um plano do ser e outro da realidade, pois isto seria a total subversão do sistema hegeliano.

O puro ser, ou puro pensar, é o próprio sujeito e o próprio objeto da lógica, ele se encapsula de tal forma que a sua conceituação se traduz em uma contradição em si mesmo. Essa característica peculiar do método dialético é indispensável para a compreensão de como o puro ser, em sua imediatidade, também pode conter uma mediação real ${ }^{13}$. Deve-se destacar, inicialmente, que o uso do termo "dialética" por Hegel sempre designa uma "auto-organização" do sujeito da matéria, sua "necessidade interna" e seu "movimento inerente" - essa é a noção logicamente básica e comezinha para que se possa compreender qualquer desdobramento dialético hegeliano ${ }^{14}$. A dialética é o que segue o conceito da coisa.

Destarte, Frederik Beiser" ${ }^{15}$ assevera que "é claramente contrário ao intento de Hegel, portanto, assumir que a dialética é uma metodologia a priori, ou, de fato, um tipo de lógica que pode ser aplicado a qualquer matéria subjetiva". Em resumo, o que o referido comentador argumenta é que a dialética é o oposto dessa concepção apriorística da realidade, ela é o movimento interno, e não uma possibilidade de exteriorização da análise conceitual. A partir da premissa que o puro saber e o puro saber são, ambos, conceitos, Juan Adolfo Bonaccini ${ }^{16}$ pontua que a unidade do conceito em si mesmo, o substrato que gera as determinações (meio pelo qual não há como se distinguir ou separá-las dessa identidade da substância) exige delas (das determinações), enquanto diferentes, e na medida em que seu conceito se põe nessa diferença, serem reciprocamente relacionadas. Ou seja, a partir da própria unidade conceitual observada é que exsurge, de determinações contrapostas, a esfera da mediação.

A princípio, pode-se contrapor de forma veemente a tal exposição alegando a sua inconsistência patente, uma vez que o puro ser não poderia ser, "concomitantemente", imediato e mediato. Antes de se adentrar na discussão sobre a inconsistência desse argumento, há de se asseverar que não há uma paridade temporal, de efeitos lógicos, quando se trata da diferenciação dos conceitos segundo Hegel. Isto é, quando se enuncia que o puro ser é imediato e mediato não se atribui nenhuma temporalidade a tal determinidade

13 WARE, R. B. Hegel: The Logic of Self-Consciousness and The Legacy of Subjective Freedom. Edinburgh: Edinburgh University Press, 1999, p.18.

${ }^{14}$ DE VRIES, W. "Hegel's Logic and Philosophy of Mind”. In: SOLOMON, Robert C.; HIGGINS, Kathleen M. (Org.). The age of German Idealism. New York: Routledge, 2003. pp.216.

${ }^{15}$ BEISER, F. Hegel. New York: Routledge, 2005, p.160.

${ }^{16}$ BONACCINI, Juan Adolfo. A Dialética em Kant e Hegel: Ensaio Sobre o Problema da Relação Entre Ser e Pensar. Natal: EdUFRN, 2000, p.151.

\begin{tabular}{|c|c|c|c|c|c|}
\hline intuitio & $\begin{array}{c}\text { ISSN } \\
1983-4012 \\
\end{array}$ & Porto Alegre & Vol.10 - $\mathrm{N}^{\mathrm{o}} .1$ & $\begin{array}{l}\text { Julho } \\
2017 \\
\end{array}$ & p. $47-67$ \\
\hline
\end{tabular}


(Bestimmtheit). Outrossim, esse movimento dialético de contradição dentro do próprio conceito não pode ser compreendida nem sob uma ótica seqüencial de que o puro ser primeiramente se apresenta imediato e que posteriormente sofre uma mediação, nem que a imediatidade e a mediatidade do conceito se conjectura de pronto de uma maneira "temporalmente igual" (algo mais próximo do conceito de "concomitância" que se poderia chegar numa descrição discursiva).

A grande implicação de se ter uma determinação tão originária quanto o puro ser é que ela surge sem que nenhuma outra categoria seja de imediato dada ${ }^{17}$. Ou seja, nenhuma outra categoria pode ser perscrutada sem que haja uma pressuposição adequada para o desenvolvimento de uma forma ordenada do pensamento. A partir disso, pode-se concatenar que a determinação, além de ser uma delimitação (imposição de finitude) é também uma negação. Não se pode olvidar, contudo, que a progressão dialética dessa análise se desenrola a dar azo à compreensão de que há um movimento ínsito a toda essa sistemática. Clarificando-se o que foi dito, a partir da imediatidade do puro ser (sua abstração mais simples), a categoria do pensamento se põe em sua imediatidade ${ }^{18}$. Todavia, há de se ressaltar que existe uma tensão envolvida nessa sistemática. Cada categoria do pensamento se coloca de maneira a afirmar um movimento, uma forma ou um conteúdo, essa forma de exposição é que leva à referida tensão.

Essa tensão deve ser compreendida dentro da conjectura dialética em que a lógica se desenvolve, mesmo que se resguarde o entendimento que há uma auto-origem ontológica do próprio ser (puro ser) a qual consiste no processo dinâmico do devir em si mesmo processando o ser em si mesmo ${ }^{19}$. Isto se dá porque a cada nova categoria posta, uma nova tensão é "gerada", de modo que se requer uma outra categoria para que se explica a consequente. Essa sistemática não recai no paradoxo do terceiro homem (também conhecido como o argumento da redução ad absurdum - hipótese em que ao se sugerir um argumento de explicação, outro argumento é sempre requerido para explicar o anterior de maneira tendente ao infinito) pelo simples fato de que a própria contradição, implicada na forma de tensão, serve para que a categoria se explique e se afirme, tanto isoladamente enquanto surge no elenco do discurso, quanto no contexto mais abrangente da dialética proposta.

Observe-se, como aponta Edgardo $\mathrm{Albizu}^{20}$, que neste ponto, a contradição não indica um dissolver-se em um nada abstrato. Ao contrário, tem-se assim "a ideia da negação da negação", que é a negação determinada e não uma simples negação vazia. $O$ sistema de conceitos anteriormente definidos segue esse caminho. A contradição deve ser concebida como o núcleo do método filosófico de Hegel ${ }^{21}$,

\footnotetext{
${ }^{17}$ HEGEL, G. W. F. Science of Logic. Tradução de W. H. Johnston e L. G. Struthers. London: George Allen \& Unwin, 1951, p.44.

${ }^{18}$ BONACCINI, Juan Adolfo. A Dialética em Kant e Hegel: Ensaio Sobre o Problema da Relação Entre Ser e Pensar. Natal: EdUFRN, 2000, p.157.

${ }^{19}$ GALLAGHER, S. Hegel, History, and Interpretation. Albany: SUNY Press, 1997, p.89.

${ }^{20}$ ALBIZU, E. Hegel, Filósofo Del Presente. Buenos Aires: Almagesto, 2000, p.125.

${ }^{21}$ HEGEL, G. W. F. Science of Logic. Tradução de W. H. Johnston e L. G. Struthers. London: George Allen \&
}

\begin{tabular}{|c|c|c|c|c|c|}
\hline intuitio & $\begin{array}{c}\text { ISSN } \\
1983-4012 \\
\end{array}$ & Porto Alegre & Vol.10 - $\mathrm{N}^{\mathrm{o}} .1$ & $\begin{array}{l}\text { Julho } \\
2017 \\
\end{array}$ & p. $47-67$ \\
\hline
\end{tabular}


uma vez que não expõe as limitações das faculdades do sujeito, como, por exemplo, o entendimento, enquanto que apenas indica a existência de um movimento da razão teórico-prática, a qual conflui para a própria realidade. Desta forma, o filósofo argentino acima citado conclui que a dialética é o próprio conteúdo em si desse método, o conteúdo que o move, em outras palavras, a dialética é a trama que envolve negações determinadas e que assim desenvolve a estrutura genético-formativa do sistema do conceito, de acordo com os preceitos lógicos-ontológicos hegelianos.

Aquilo que congrega a definição de começo absoluto da lógica, a própria relação já estabelecida da unidade do puro saber, puro ser, bem afirma $\mathrm{Hegel}^{22}$, deve ser algo conhecido. Ao se falar em algo conhecido, logo se depreende que isso também é algo concreto, o que acarreta a compreensão que isto carrega consigo várias determinações. Desta feita, essa relação, tida como o próprio começo, pressupõe-se como algo conhecido, e que por ela mesma está dada por imediato.

Nesse passo, tomando por base que a relação está unicamente posta entre coisas diferentes, como anteriormente abordado dialeticamente, deve-se depreender que ela contém em si mesma a própria mediação desse sistema. Assim sendo, é de grande valia discorrer brevemente como essa mediação influencia o próprio método de contradição e seu conteúdo dialético, isto porque, a própria imediaticidade envolve, em alguma gradação, algum modo de mediação, algo que, indubitavelmente, exsurge em algum momento no estudo da lógica hegeliana. Beiser $^{23}$ indica que a unidade da análise é ambiguamente incondicionada e condicionada, dependente e independente, haja vista que nesse elemento de contradição intrínseco ao sistema, só de pode encontrar essa dupla consideração acerca do conteúdo dialético (negativamente posto).

Ressalte-se, portanto, que a tensão age como meio de propalar os desdobramentos existentes entre as categorias. Desta feita, a partir da tensão existente entre o ser e o nada, o imediato e o mediato, identidade e diferença, ocorre um permanente e contínuo avançar e retroceder. Por isso é correto asseverar que existe uma circularidade inerente ao processo lógico desenvolvido. Essa circularidade, por sua vez, colapsa em um simples pensamento, em uma unidade ${ }^{24}$. Ou seja, há de se compreender que a inerência lógica que tende a circularidade já é um elemento inserto na própria exposição ontológica hegeliana.

A partir da análise dessa circularidade se percebe que a mediação existente na própria imediatidade propicia a existência desse avançar e retroceder perene. A verdade inicial, encontrada na imediatidade das categorias mais abstratas, não é diferente do seu resultado ${ }^{25}$. Esse resultado também é a

Unwin, 1951, p.45.

${ }^{22}$ HEGEL, G. W. F. Science of Logic. Tradução de W. H. Johnston e L. G. Struthers. London: George Allen \& Unwin, 1951, p.51.

${ }^{23}$ BEISER, F. Hegel. New York: Routledge, 2005, p.168.

${ }^{24}$ BURBIDGE, J. W. The Logic of Hegel's Logic: An Introduction. Peterborough: Broadview Press, 2006, p.39.

${ }^{25}$ HEGEL, G. W. F. Science of Logic. Tradução de W. H. Johnston e L. G. Struthers. London: George Allen \& Unwin, 1951, p.60.

\begin{tabular}{|c|c|c|c|c|c|}
\hline intuitio & $\begin{array}{c}\text { ISSN } \\
1983-4012\end{array}$ & Porto Alegre & Vol.10 - $\mathrm{N}^{\mathrm{o}} .1$ & $\begin{array}{l}\text { Julho } \\
2017\end{array}$ & p. $47-67$ \\
\hline
\end{tabular}


própria verdade, pois, se não o fosse, não haveria nenhuma referência gráfica ao círculo. Essa "verdade resultante" se distingue apenas da "verdade inicial" em função da especificação completa de seu conteúdo ${ }^{26}$. Pode-se apontar que o simples avanço e retrocesso, em última instância, nada mais são do que um não-ser ou uma contradição (no sentido vulgar da palavra, e não no sentido dialético próprio), embora não haja nenhuma correspondência direta entre o não-ser e a contradição. Ou seja, para a entenda que a explanação do movimento da tensão categorial, a única forma de apresentá-lo sem que se recaia em um vilipêndio da compreensão geral do senso comum, é colocá-lo como uma representação circular desse movimento - círculo de autoperpetuação nas palavras de Burbidge ${ }^{27}$.

Assim sendo, cada tensão categorial deve atravessar esse postulado básico da ligação circular de cada um desses momentos. A cada apresentação categorial diferente tanto a imediatidade, em sua representação mais simples e abstrata, quanto a mediatidade, denotada a partir de cada emprego sucessivo e circular de novas categorias, remanesce plenamente preservada, explicada e condicionada ao próprio sistema conceitual posto.

\section{Delineamentos do Ser e do Nada: Uma Abordagem Conceitual dos Signos Metafísicos Hegelianos}

O ser, tal como abordado na seção anterior, é o imediato indeterminado, é a determinação mais abstrata que poderia ser aposta a qualquer categorização metafísica, principalmente quando se trata de uma determinação essencialista desse ramo. Essa vacuidade patente, que o possibilitava estar livre para alcançar o interior dentro de si mesmo, indica que esse puro ser é desprovido de "qualidade". Isto é, na verdade, essa constituição própria já pode ser qualificada como uma forma de qualificação, todavia, ela não é suficiente para as determinações mais específicas de uma oposição entre o ser mais abstrato como analisado e o ser determinado como tal. Em resumo, o ser em sua acepção mais abstrata, o mais puro ser, não determina algo propriamente dito, logo, não determina a existência de nada.

Não obstante, John W. Burbidge ${ }^{28}$ aponta que a "qualificação" do ser define a sua realidade, ainda que, ao mesmo tempo, partindo do pressuposto que ela indica um limite para o próprio ser, outrora indefinido por completo. Outrossim, essa qualificação, de algum modo, pode ser igualmente definida como a sua negação. Em um estágio primitivo, a qualificação se foca na realidade do ser qualificado bem como também em sua limitação e sua negação ${ }^{29}$. O dito ser qualificado é aquilo que pode ser denominado de "algo", tido como um conceito unificado singular. Nesse horizonte, para que se possa alcançar uma

\footnotetext{
${ }^{26}$ BONACCINI, Juan Adolfo. A Dialética em Kant e Hegel: Ensaio Sobre o Problema da Relação Entre Ser e Pensar. Natal: EdUFRN, 2000, p.160.

${ }^{27}$ BURBIDGE, J. W. The Logic of Hegel's Logic: An Introduction. Peterborough: Broadview Press, 2006, p.40.

${ }^{28}$ BURBIDGE, J. W. The Logic of Hegel's Logic: An Introduction. Peterborough: Broadview Press, 2006, p.42.

${ }^{29}$ UCHIDA, H. Marx's Grundrisse and Hegel's Logic. New York: Routledge, 1988, p.148.
}

\begin{tabular}{|c|c|c|c|c|c|}
\hline intuitio & $\begin{array}{c}\text { ISSN } \\
1983-4012\end{array}$ & Porto Alegre & Vol.10 - No.1 & $\begin{array}{l}\text { Julho } \\
2017\end{array}$ & p. 47-67 \\
\hline
\end{tabular}


compreensão mais robusta da diferença entre o ser qualificado e a existência (Dasein), embora que isso seja algo que Hegel ${ }^{30}$ só trate de forma detida na segunda seção da Ciência da Lógica, e, portanto, não seja um ponto específico do estudo em progresso, deve-se delimitar, ainda que perfunctoriamente, e até exemplificativamente, como há uma diferenciação de tal sorte.

É lição comezinha que o senso comum costuma aproximar (para não se ser categórico ao asseverar que nessa forma de entendimento vulgar não há nenhuma espécie de compreensão mais apurada do tema) as definições de ser e de existência. Ou seja, é usual que na exposição do senso comum tudo que é alguma coisa, seja tido necessariamente por existente. Contudo, essa generalização da existência em concordância com o ser não alcança uma qualificação filosófica acurada, principalmente quando se perscruta os meandros da filosofia hegeliana, hipótese em que tal aproximação é inviável e inaceitável.

O ser, em sua abstração mais elevada, como já repetido até exaustivamente no presente trabalho, não apresenta a denominação suficiente para indicar algo que seja alguma coisa, por isso mesmo que há a sua equivalência ao nada. Assim sendo, mesmo havendo a sua denominação qualitativa, que será mais bem analisada adiante, não se quer dizer que haja a sua equivalência para com a existência. De modo exemplificativo, o próprio pensamento pode formular hipóteses de que algo é, mas disso não decorre que isso que é necessariamente exista. Assim, pode-se pensar em um ser totalmente abstrato (desde que qualificado como "algo") que não tenha nenhuma correspondência, ainda que mínima com a realidade, como um unicórnio ou uma fada.

Pode-se pensar que eles sejam algo, pois, quando se pensa em um unicórnio pode-se até descrevêlo de uma maneira pormenorizada e minuciosa. O unicórnio pensado pode possuir pelo azul, ondulado, com um chifre brilhante fluorescente ou pensar que uma fada carrega uma varinha mágica de um metro de comprimento e possui um chapéu pontudo e vermelho, os elementos "definidores" e "qualificadores" a serem utilizados nessa exemplificação são infinitos. Outrossim, esses seres, tais como pensados, não exibem nenhuma propriedade com a realidade, de modo que não existem. A sua inexistência está, portanto, condicionada a impossibilidade de que eles possam congregar os elementos mínimos necessários para que compartilhem a própria existência $\left(\right.$ Dasein $\left.^{3 l}\right)$ do seu ser. Muito embora não se esteja tratando no trabalho em curso de nenhuma aproximação, comparação, crítica ou análise distintiva da filosofia antimetafísica de Martin Heidegger dos elementos ou estruturas essenciais do pensamento de Hegel, há de se brevemente pontuar que, apesar de ambos utilizarem o mesmo termo Dasein, e ainda que a filosofia de Heidegger seja uma analítica-existencial, não se deve confundir as duas determinações. Até mesmo em termos de tradução há uma distinção bastante clara, o Dasein heideggeriano é usualmente traduzido como

\footnotetext{
${ }^{30}$ HEGEL, G. W. F. Science of Logic. Tradução de W. H. Johnston e L. G. Struthers. London: George Allen \& Unwin, 1951, p.140.

${ }^{31}$ HEIDEGGER, M. Ser e Tempo. Tradução de Márcia Sá Cavalcante Schuback. 3. ed. Rio de Janeiro: Vozes, 2008, p.35.
}

\begin{tabular}{|c|c|l|l|l|l|}
\hline intuitio & $\begin{array}{c}\text { ISSN } \\
1983-4012\end{array}$ & Porto Alegre & Vol.10- No.1 & $\begin{array}{l}\text { Julho } \\
2017\end{array}$ & p. $47-67$ \\
\hline
\end{tabular}


ser-aí (ou presença, na tradução do original apresentada por Márcia Schuback), já a tradução de Dasein tal como Hegel utiliza segue as traduções já empregadas em textos kantianos, e representa puramente existência. Ao contrário do conceito hegeliano, o ser-aí de Heidegger não é algo encapsulado conceitualmente, não é algo fechado e determinado, até porque as suas condições de decisão possibilitam tal abertura do ser.

A simples operação mental de "imaginar" algo que seja, tal como na exemplificação dada, não é suficiente para que se possa peremptoriamente asseverar que aquilo é algo existente. Não há essa correspondência inerente ao sistema dialética hegeliano, muito embora, seja claro que no senso comum tal espécie de aproximação seja corriqueira. Após essa breve explanação acerca da qualidade do ser (e de sua diferenciação da existência), pode se passar ao estudo conjunto do ser do nada e do devir. A explanação pretérita, ainda que não se relacione diretamente com os aspectos dialéticos da definição de identificação do ser para com o nada, auxilia no entendimento da concepção do ser no sentido exposto por Hegel ${ }^{32}$, e que mesmo quando determinado ele não se equivale às disposições do senso comum.

O ser em virtude de ser tido como o imediato indeterminado, é, na realidade, o próprio nada. Em sua interioridade ele é igual a si mesmo e não é desigual frente ao nada, não tem nenhuma diferença para com ele. É a indeterminação em sua acepção mais pura, ou seja, o puro vazio (ou pura vacuidade). Não há "outra coisa" que se possa pensar sobre ele que não seja o próprio vazio ou o próprio nada. Juan Adolfo Bonaccini ${ }^{33}$ pontua com propriedade que a imediatidade do ser o obriga a ser carente de determinação, e, deste modo, ele ainda está para começar a ser um momento elementar qualquer. O nada, por seu turno, é a simples igualdade vazia consigo mesma. É a total ausência de determinação e de conteúdo. É a indistinção daquilo que por não ser determinado, nada o é.

A partir dessas duas amostras do ser e do nada, não se pode concluir algo diverso da sua identificação e da sua igualdade, ou seja, dito de maneira direta e clara: o ser é o nada e o nada é o ser. O ser só pode ser considerado como oposto ao nada, e, reciprocamente, o nada em oposição ao ser, caso se tenha cada um determinadamente posto de forma unilateral e externa ao sistema dialético em que se inserem somente nessa hipótese eles são elementos que se opõem. Ou seja, o nada somente se opõe, unilateralmente, a algo que esteja determinado, a oposição se dá contra "algo" e não contra o puro ser, que, por ser desprovido de determinação, encontra sua igualdade no próprio nada.

Para melhor explanar essa passagem, há de se ter em mente que existe uma diferenciação significativa entre a oposição e a contrariedade. A contrariedade se dá de maneira interna dentro da sistemática lógica, de modo que, mesmo se equivalendo, o puro ser se põe de forma contrária ao puro

${ }^{32}$ HEGEL, G. W. F. Science of Logic. Tradução de W. H. Johnston e L. G. Struthers. London: George Allen \& Unwin, 1951, p.49.

${ }_{33}$ BONACCINI, Juan Adolfo. A Dialética em Kant e Hegel: Ensaio Sobre o Problema da Relação Entre Ser e Pensar. Natal: EdUFRN, 2000, p.163.

\begin{tabular}{|c|c|l|l|l|l|}
\hline intuitio & $\begin{array}{c}\text { ISSN } \\
1983-4012\end{array}$ & Porto Alegre & Vol.10- No.1 & $\begin{array}{l}\text { Julho } \\
2017\end{array}$ & p. 47-67 \\
\hline
\end{tabular}


nada, pelo fato de ser ele mesmo e ser outro (na unidade lógica do devir). Porém, a oposição não ocorre por dentro dessa análise intrínseca do sistema, ela apenas é grassada quando se coloca em comparação termos diversamente determinados, ou seja, algo determinado em confronto com outra determinação. O ser determinado pode se opor ao nada determinado (bem como tomado no senso comum, como a ausência de "alguma coisa"), pois, nesse caso se teria uma oposição de algo para com algo. Diferentemente do que ocorre na análise do puro ser e do puro nada, em que, por falta de determinidade, inexiste essa oposição propriamente dita de algo para com algo determinado. Edgardo Albizu ${ }^{34}$ destaca que o núcleo da tese de Hegel acerca do começo lógico se cifra nessa ideia de igualdade entre o ser o nada, outrossim, sem essa equivalência lógico-ontológico não haveria fundamentação para o lógos no sistema hegeliano, haja vista que dessa inter-relação auto-contida derivam as demais explanações categoriais do referido filósofo alemão.

Nesse panorama nuclear da metafísica hegeliana, há de se extrair como o fez o supramencionado comentador que o ser e o nada são os signos essenciais da filosofia ${ }^{35}$. Por signos não há que se depreender que de plano o ser o nada determinem algo, ou venham a se desdobrar, cada um por si, em significações diversas que originariam outras categorias, sejam objetivas ou subjetivas. Não obstante, tais signos apenas permitem que seu próprio significado seja pensado enquanto tal. Eles possibilitam a caracterização significante do objeto-ente da razão-pensante e assim dar suporte à empreitada teórica de erguer uma estrutura semântica da linguagem. Isto é, o ser e o nada são "proto-signos", o que equivale enunciar que eles, em sua unidade conceitual, são os operadores mínimos do sistema lógico (com desdobramentos de ordem ontológica e de linguagem) proposto por Hegel ${ }^{36}$.

Indubitavelmente, para que se aceite essa ideia de Edgardo Albizu, há de se acatar uma roupagem (ou interpretação) saussureana para a metafísica hegeliana. Ou seja, o signo, seja o nada ou o ser, mantém em si unido um componente conceitual da configuração sensível (estando intrinsecamente relacionado com os sentidos) que o sujeito adjudica - nesse mesmo sentido, Stephen Houlgate ${ }^{37}$ acrescenta que a linguagem nessa compreensão é o sistema de signos pelos quais o entendimento se articula, ou seja, a significação de ser e nada é o elemento lógico mínimo em tal manuseio da linguagem. De acordo com essa concatenação lógica, o componente conceitual representa diversas variantes constitucionais. Os significantes advindos do ser e do nada significam, portanto, a própria operação que eles desencadeiam, e não aquilo que eles não tenham feito.

\footnotetext{
${ }^{34}$ ALBIZU, E. Hegel, Filósofo Del Presente. Buenos Aires: Almagesto, 2000, p.144.

${ }^{35}$ HEGEL, G. W. F. Science of Logic. Tradução de W. H. Johnston e L. G. Struthers. London: George Allen \& Unwin, 1951, p.19.

${ }^{36}$ HEGEL, G. W. F. Science of Logic. Tradução de W. H. Johnston e L. G. Struthers. London: George Allen \& Unwin, 1951, p.34.

${ }^{37}$ HOULGATE, S. The Opening of Hegel's Logic: From Being to Infinity. West Lafayette: Purdue University Press, 2006, p.75.
}

\begin{tabular}{|c|c|c|c|c|c|}
\hline intuitio & $\begin{array}{c}\text { ISSN } \\
1983-4012\end{array}$ & Porto Alegre & Vol.10 $-\mathrm{N}^{\circ} .1$ & $\begin{array}{l}\text { Julho } \\
2017\end{array}$ & p. $47-67$ \\
\hline
\end{tabular}


O ser não passou ao nada, porque é o próprio nada, enquanto que o nada não passou a ser porque é o próprio ser. As operações de passagem do ser ao nada e do nada ao ser, como adiante será mais bem explicado, só se afiguram possíveis a partir da interconexão com a unidade conceitual do devir. Por isso que é importante observar que, segundo essa explanação de significância do ser e do nada, não há o referido trespasse, algo que não se opera de pronto a partir da colocação abstrata dos dois elementos. Assim sendo, ainda que não se possa representar o ser ou o nada, dada a sua vacuidade mais imediata, a sua indeterminação característica, o seu posicionamento como proto-signo primordial, tal como delineado, é que possibilita a sua colocação discursiva dentro da proposição metafísica hegeliana ${ }^{38}$. Caso não se pudesse operar o ser e o nada conceitualmente como sendo essa ferramenta básica da lógica, por óbvio, que não seria possível encontrar nenhuma unidade de desdobramento de tais operadores, como será observado na dialética do ser-nada-devir ${ }^{39}$. Impende destacar, por conseguinte, que a abstração tão imediata e indeterminada do ser, a qual o coloca como começo absoluto do sistema lógico, finda por apor tal estratificação básica no sentido de uma mediação abstrata (tal como sutilmente indicado na seção anterior do trabalho em comento). Não obstante, o puro ser, é tão fortemente puro em sua abstração que termina por se dissolver em sua própria indeterminabilidade.

Todavia, não se pode pensar que essa dissolução do próprio puro ser equivale a dizer que ele transita de pronto em sua "direção contrária”, como o faz Juan Adolfo Bonaccini ${ }^{40}$. Há uma contrariedade na dialética hegeliana, como mais adiante será perscrutado, no entanto, há certa incoerência em se asseverar que haja um direcionamento em tal contrariedade, uma vez que isso implicaria dizer que há espacialidade em tal contrariedade.

Não se pode asseverar, enquanto se esteja tratando inicialmente apenas do ser e do nada, que haja um movimento contrário entre eles, como se houvesse alguma espacialidade imbuída nisso. Ainda que se tenha comentado que havia uma circularidade na questão das contraposições de imediatidade e mediatidade e de identidade e diferença, tal como se disse que não havia temporalidade nessa abordagem, há de se salientar que na análise de equivalência do ser e do nada também não há nenhuma indicação de espaços contrários entre os dois elementos. Nesse mesmo sentido de inadmitir a identificação espacial do trespasse do ser ao nada se coloca Stephen Houlgate ${ }^{41}$ ao asseverar categoricamente que a lógica hegeliana não se presta a tratar de conceitos de espacialidade (nem de temporalidade, acrescenta o referido filósofo americano). Essa espacialidade somente teria seu uso acertado na terminologia hegeliana caso estivesse a

${ }^{38}$ HARTNACK, J. An Introduction to Hegel's Logic. Tradução de Lars Ågård-Mogensen. Indianapolis: Hackett, 1998, p.15.

${ }^{39}$ HEGEL, G. W. F. Science of Logic. Tradução de W. H. Johnston e L. G. Struthers. London: George Allen \& Unwin, 1951, p.24.

${ }^{40}$ BONACCINI, Juan Adolfo. A Dialética em Kant e Hegel: Ensaio Sobre o Problema da Relação Entre Ser e Pensar. Natal: EdUFRN, 2000, p.164.

${ }^{41}$ HOULGATE, S. The Opening of Hegel's Logic: From Being to Infinity. West Lafayette: Purdue University Press, 2006, p.12.

\begin{tabular}{|c|c|c|c|c|c|}
\hline intuitio & $\begin{array}{c}\text { ISSN } \\
1983-4012\end{array}$ & Porto Alegre & Vol.10 $-\mathrm{N}^{\circ} .1$ & $\begin{array}{l}\text { Julho } \\
2017\end{array}$ & p. 47-67 \\
\hline
\end{tabular}


fazer referência a um ser determinado (Dasein) dentro da colocação de cada ser em específico. Isso porque, essa espécie de ser determinado (ser-existente) é exitosa em colocar o ser dentro da determinação espacial de algo a ser descrito discursivamente. Contudo, essa não foi a intenção de Bonaccini ao colocar o termo "direção contrária" dentro da sua explanação da transitoriedade do ser ao nada.

A sua igualdade de dissolução irá convergir para um trespasse entre um e outro conceito, tal como se verá a partir da dialética proposta em sua junção com o devir. No entanto, isso não leva à conclusão de que haja uma questão de espaço a ser tratada nesse trespasse, até porque, esse "movimento" é meramente conceitual entre estruturas básicas do pensamento ${ }^{42}$, as quais não estão brevemente pontuadas em um sistema cartesiano de coordenadas (aliás, um sistema cartesiano de coordenadas é tudo que Hegel tenta espargir de sua conceituação lógico-ontológica, afinal, tal sistematização inexoravelmente conduz à dualidade da adequação que o filósofo alemão se esforça tanto em combater).

Não se deve a partir dessa objeção se compreender que não haja um movimento categorial ínsito a essa operação de dissolução e traspasse do ser ao nada. Isso é algo patente dentro da lógica hegeliana, é urgente e necessário para que o sistema opere dentro das bases dialéticas outrora estabelecidas. Sem essa conjecturação mínima de que o ser, por abstração mais simples que se possa ter, já está inserido no processo desde o começo não seria possível empreender o seu trânsito ao nada, em sua equivalência categorial. Sem essa dissolução e sem esse movimento o ser não seria equivalente ao nada. Assim sendo, tendo o enquadramento lógico de que o ser, ao se dissolver em sua apresentação imediata de indeterminação, acaba por se encontrar no próprio nada, e, o nada, por sua vez, por ser tão abstrato, indeterminado e imediato como o próprio ser, também finda por nele se trespassar, que há a indicação de uma unidade resolutiva desse movimento categorial: o devir.

Essa primeira concretude do ser, tal como pode ser percebido qualitativamente, é a congruência lógica dos dois "momentos" básicos das estruturas do pensamento (ser e nada), de maneira que o estudo de tal complementação dos opostos, dentro da circularidade dialética já apresentada, será o tema da abordagem do tópico vindouro.

\section{A Dialética do Ser, Nada e Devir: Uma Apresentação da Unidade Lógica}

Partindo do pressuposto essencial que o puro ser e o puro nada são identicamente iguais, como já abordado anteriormente, e cada um desses momentos tende a se dissolver no outro, ao haver a transição do ser ao nada e do nada ao ser. Esse movimento de trânsito foi denominado por Hegel de "dupla transição",

${ }^{42}$ HEGEL, G. W. F. Science of Logic. Tradução de W. H. Johnston e L. G. Struthers. London: George Allen \& Unwin, 1951, p.60.

\begin{tabular}{|c|c|c|c|c|c|}
\hline intuitio & $\begin{array}{c}\text { ISSN } \\
1983-4012\end{array}$ & Porto Alegre & Vol.10 - $\mathrm{N}^{\mathrm{o}} .1$ & $\begin{array}{l}\text { Julho } \\
2017\end{array}$ & p. $47-67$ \\
\hline
\end{tabular}


afinal, o movimento de nada ao ser e do ser ao nada é igual, a transição opera igualmente entre os dois elementos lógicos de maneira exatamente igual e indistinguível.

John W. Burbidge ${ }^{43}$ comenta que estes movimentos de transição entre os operadores lógicos (semelhantemente como Kant identificou como sendo o trabalho do entendimento) captura a "síntese" 44 e a concebe como um unidade singular, que é o próprio devir. Assim sendo, seria impossível se iniciar a análise dialética de Hegel ${ }^{45}$ apenas pela simples constatação do devir, ou partir de seus desdobramentos categoriais. Pois, o pensamento possui de forma inelutável três origens categoriais, que são os dois operados lógicos básicos que se contradizem, e a categoria unitária do devir, que os resolve em sua contradição e possibilita as demais reverberações lógicas.

Todavia, há de se questionar, como bem o faz Juan Adolfo Bonaccini ${ }^{46}$, o porquê de o ser e o nada, apesar de ter sido tão exaltado que eles eram idênticos, serem considerados como contraditórios (ou contrários, do ponto de vista estritamente formal, ou seja, sem uma percepção unitária externa ao processo do pensamento). A colocação como contrários entre esses operados lógicos consiste na sua própria equalização de identidade. Explique-se, já que o puro ser, por não determinar nada e por ser totalmente imediato se equivale ao puro nada, dada a sua vacuidade elementar, ele é tanto o puro ser quanto o seu contrário. A contradição existente se coloca no "fato" de ele ser ele mesmo e o seu contrário no seu próprio momento lógico, podendo ser traspassado de uma para outra categoria de maneira totalmente incondicionada.

O devir, dentro dessa conjunção de momentos lógicos, engloba a dupla transição do ser ao nada e do nada ao devir, ele é que promove a unidade lógica entre ambos, de maneira que se permaneça resguardada a capacidade de o ser igualar-se ao nada e o nada se igualar ao $\operatorname{ser}^{47}$. Isso porque, tão necessário quanto essa igualdade de ser e nada, o devir garante que haja o "começando a ser" (sob a perspectiva nada-ser) e o "vindo ao nada" (sob a perspectiva contrária do ser-nada). Essas são as operações que Burbidge ${ }^{48}$ coloca, ainda que num plano de secundarismo, como sendo "recíprocas e mutuamente requeridas para cada um", tendo por consideração que estes movimentos especulativos

\footnotetext{
${ }^{43}$ BURBIDGE, J. W. The Logic of Hegel's Logic: An Introduction. Peterborough: Broadview Press, 2006, p.40.

${ }^{44}$ Muito embora seja comum se falar em tese, antítese e síntese sempre que se refere à dialética hegeliana esses termos devem ser usados com certa parcimônia, haja vista que podem assumir considerações diversificadas quando comparados com outros sistema dialéticos, como, por exemplo, quando se opera a comparação entre essas operações do pensamento em Hegel e Kant.

${ }^{45}$ HEGEL, G. W. F. Science of Logic. Tradução de W. H. Johnston e L. G. Struthers. London: George Allen \& Unwin, 1951, p.68.

${ }^{46}$ BONACCINI, Juan Adolfo. A Dialética em Kant e Hegel: Ensaio Sobre o Problema da Relação Entre Ser e Pensar. Natal: EdUFRN, 2000, p.166.

${ }^{47}$ BRINKMANN, K. "The Dialetic of the Inverted World and The Meaning of Aufhebung". In: LIMNATIS, N. The Dimensions of Hegel's Dialectic. New York: Continuum, 2010, p.139.

${ }^{48}$ BURBIDGE, J. W. The Logic of Hegel's Logic: An Introduction. Peterborough: Broadview Press, 2006, p.41.
}

\begin{tabular}{|c|c|c|c|c|c|}
\hline intuitio & $\begin{array}{c}\text { ISSN } \\
1983-4012\end{array}$ & Porto Alegre & Vol.10 $-\mathrm{N}^{\circ} .1$ & $\begin{array}{l}\text { Julho } \\
2017\end{array}$ & p. 47-67 \\
\hline
\end{tabular}


posicionam o estágio sintético (devir) para o entendimento vindouro do esquema dialético a partir dessa habilidade integrativa.

Por haver no devir a conservação de dois momentos lógicos distintos-equivalentes, ele deve ser tido como o primeiro conteúdo lógico a ser compreendido do ser e do nada, haja vista que é a própria união de ambos os elementos básicos. Edgardo Albizu ${ }^{49}$ discorda de forma veemente dessa compreensão que o devir é o primeiro conteúdo lógico existente. Para ele, o devir é apenas a proto-opção metafísica de Hegel diante da lógica. Essa concepção só é possível porque para Albizu o pensamento e sua reflexão são exteriores aos processos estritamente lógico-operativos, de modo, que existem, temporalmente, protosignificantes vazios que pertencem a esse sistema e que os precedem. A partir dessa abordagem, o devir destrói e desintegra esses protosignificantes temporais. Apesar de esse filósofo trabalhar com uma ideia particular de significação, até em certo ponto acertada, como colocada na seção precedente, ele se equivoca ao colocar elementos de temporalidade e exterioridade na apresentação do devir ${ }^{50}$. Caso se assuma que não há correção nessa colocação, o devir não vem simplesmente a destruir essa vacuidade de elementos protosignificantes. Ele vem, apenas, para congregar a contradição-equivalência existente nos próprios operados lógicos (que não deixam de ser signos) ao se inserirem em tal sorte de conjunção unitária.

Espargindo as críticas ao primeiro conteúdo lógico do sistema, chega-se à conclusão de que o devir também se apresenta como sendo a primeira verdade do referido método sistemático-lógico da metafísica hegeliana. Há de se relembrar que a verdade sob esse enfoque dialético não pode tentar ser concebida como a adequação entre sujeito e objeto, dentro de um enunciado simplesmente posto. A verdade colocada nessa conjunção de momentos lógicos é a própria totalidade exibida pelo sistema ${ }^{51}$. A verdade consiste no ser se equivaler ao nada e dele se diferenciar, haja vista que um desaparece no outro, não sedo mais o mesmo.

A vacuidade inerente de cada um dos momentos os coloca como iguais e equivalentes, todavia, no trespasse recíproco de cada um em busca do seu momento contrário, cada um é determinado (de forma diversa) em comparação com o outro, tenha havido ou não a finalização do movimento de trespasse. Seja no início ou no final desse movimento de trespasse a igualdade e a diversidade do ser e do nada remanesce a mesma, de maneira que o devir se perfectibiliza como verdade lógica a partir do momento de que o pensamento o coloca como unidade lógica singular. Outro ponto da argumentação metafísica de Hegel ${ }^{52}$

\footnotetext{
${ }^{49}$ ALBIZU, E. Hegel, Filósofo Del Presente. Buenos Aires: Almagesto, 2000, p.167.

${ }^{50}$ FOSTER, M. N. Hegel's Idea of Phenomenology of Spirit. Chicago: The University of Chicago Press, 1998, p.37.

${ }^{51}$ BONACCINI, Juan Adolfo. A Dialética em Kant e Hegel: Ensaio Sobre o Problema da Relação Entre Ser e Pensar. Natal: EdUFRN, 2000, p.167.

${ }^{52}$ HEGEL, G. W. F. Science of Logic. Tradução de W. H. Johnston e L. G. Struthers. London: George Allen \& Unwin, 1951, p.72.
}

\begin{tabular}{|c|c|c|c|c|c|}
\hline intuitio & $\begin{array}{c}\text { ISSN } \\
1983-4012\end{array}$ & Porto Alegre & Vol.10 $-\mathrm{N}^{\circ} .1$ & $\begin{array}{l}\text { Julho } \\
2017\end{array}$ & p. 47-67 \\
\hline
\end{tabular}


que deve ser revisitada após o estabelecimento da unidade lógica do devir é o começo desse ramo filosófico. Como anteriormente assentado, o começo absoluto deve ser encontrado no puro ser.

Essa assertiva é verdadeira no sentido de que, logicamente, o puro ser precede o nada e o devir dentro de seu encadeamento sistemático. Todavia, o postulado do Absoluto em sua imediatidade não é mais apenas o puro ser, e sim, o devir. Isso ocorre porque o devir, ao conglobar indistintamente o ser e o nada, oferece a fundamentação adequada para o Absoluto. Apesar de já se ter discorrido de maneira detida acerca do estabelecimento do devir como um conteúdo verdadeiro de unidade lógica do sistema metafísico hegeliano ainda pode remanescer a dúvida se tal exposição filosófica finda ou não por vilipendiar o princípio da não-contradição, estatuído nos meandros acadêmicos há bastante tempo.

Para que essa dúvida seja sanada a contento é preciso revolver mais uma vez a questão da temporalidade dentro do contexto do ser-nada-devir de Hegel. Para que haja uma violação ao princípio da não-contradição (isto é, dito de outra forma, para que haja efetivamente uma contradição) é necessário que algo seja afirmado e negado concomitantemente.

É necessário, portanto, que se envolva um componente temporal na conclusão positiva ou negativa de algo a ser dito. Como anteriormente já foi levantado, Hegel ${ }^{53}$ pretende construir as bases de sua ontologia-lógica apartando-se dos limites da temporalidade. Por isso mesmo que o seu começo se dá no Absoluto, sua fundação independe do componente temporal para que seja estatuída de maneira válida e prevalente.

A indicação de $\operatorname{Hegel}^{54}$ que existe uma contradição ínsita entre ser e nada não leva a conclusão de que o princípio da não-contradição está sendo violado, apesar de essa ser a conclusa mais aparente que se possa retirar da simples disposição gramatical desses termos. Aprofundando-se mais um pouco nessa questão, há de se notar que a contradição existente entre o ser e o nada, como operadores lógicos básicos que ao se igualarem se contrariam um ao outro, existe apenas dentro do próprio movimento dialético de trespasse de um operador ao outro.

Nessa operação interna não há temporalidade envolvida, por isso, pode-se compreender que a contradição existente não se amolda exemplificativamente ao conceito de contradição requerido pelo supramencionado princípio lógico. Destarte, o princípio da não-contradição só será exercitável quando se tratar do ser propriamente determinado como algo, haja vista que nessa hipótese de ocorrência lógica a sua determinação poderá ser contraditada com outro ser determinado. De maneira que, temporalmente falando, esse princípio poderá ser o óbice para que essa espécie de contradição ocorra sem que haja mácula ao sistema.

\footnotetext{
${ }^{53}$ HEGEL, G. W. F. Science of Logic. Tradução de W. H. Johnston e L. G. Struthers. London: George Allen \& Unwin, 1951, p.90.

${ }^{54}$ HEGEL, G. W. F. Science of Logic. Tradução de W. H. Johnston e L. G. Struthers. London: George Allen \& Unwin, 1951, p.81.
}

\begin{tabular}{|c|c|c|c|c|c|}
\hline intuitio & $\begin{array}{c}\text { ISSN } \\
1983-4012\end{array}$ & Porto Alegre & Vol.10 $-\mathrm{N}^{\circ} .1$ & $\begin{array}{l}\text { Julho } \\
2017\end{array}$ & p. 47-67 \\
\hline
\end{tabular}


A Dialética do Ser-Nada-Devir: Desdobramentos da Ciência da Lógica de Hegel

O ser e o nada poderiam se diferenciar no tempo, caso isso fosse possível numa análise exteriorizada de suas operações lógicas, todavia, sendo certo que o ser e o nada formam a unidade lógica do devir, a sua abstração mais imediata (seja do ser ou do nada) apenas conduzem à afirmação do próprio conteúdo absoluto, que é o devir ${ }^{55}$. A aparente ofensa ao princípio da não-contradição também é fortemente influenciada e concatenada pela própria linguagem comum (a linguagem desprovida do senso filosófico requerido para que se opere a metafísica). Isso porque suas imprecisões e colocações dispersivas findam por retirar, ou ao menos desviar a atenção, da característica reflexiva do ser e do nada. Afinal, na linguagem comum é um absurdo se ter a concepção de que o ser equivale ao nada e que o nada é igual ao ser.

Essas definições comuns não alcançam a necessidade ontológica de depuração do ser mais abstrato e do nada em sua maior abstração também. Por esse motivo que a característica reflexiva desses operadores lógicos finda por se dispersar nessa compreensão incompleta e rasurada da realidade em termos filosóficos ${ }^{56}$. Assim sendo, a assertiva de $\mathrm{Hegel}^{57}$ que o ser e o nada não são o mesmo e são o mesmo acaba por ser algo incompreensível para o entendimento comum ${ }^{58}$. O problema de sempre se inclinar a colocar tal assertiva no bojo da rejeição do princípio da não-contradição reside na própria não compreensão da verdade lógica contida no devir.

O ser e o nada não expressam a sua verdade em sua acepção unilateral, outrossim, não há uma verdade no ser e uma outra verdade no nada, como seria possível se pensar temporalmente em um único e distinto momento de cada um dos operadores lógicos, segundo essa forma perfunctória de entendimento. A verdade está contida no trespasse entre um momento lógico e o outro, do ser ao nada e do nada ao devir, de maneira que ela se congrega unitariamente posta no devir. O devir que é o conteúdo lógico por excelência, e por isso, pode carregar em si próprio a verdade sistematicamente debatida. Não há espaço, portanto, para se concluir que haja uma dissonância da verdade alcançada em sua contraposição aos momentos lógicos de transição do ser e do nada, basicamente porque o princípio da não-contradição não consegue abarcar esse movimento circular dialético. Assim, não há que se dizer que o ser equivaler ao nada, e vice-versa, na dialética hegeliana conduz à ofensa do princípio da não-contradição tal como formulado na história da lógica formal nos meandros filosóficos, simplesmente porque não há

\footnotetext{
${ }^{55}$ GALLAGHER, S. Hegel, History, and Interpretation. Albany: SUNY Press, 1997, p.76.

${ }^{56}$ Não que haja duas realidades distintas, uma realidade do senso comum e outra realidade dedicada apenas a explicar e explanar as concatenações metafísicas, o que se importa salientar com o termo "realidade filosófica" é que a linguagem comum não consegue expressar, de maneira totalmente escorreita, certos temas (e por vezes "filosofemas") indispensáveis para que a lógica-ontológica seja compreendida em sua máxima extensão do pensamento puro.

${ }^{57}$ HEGEL, G. W. F. Science of Logic. Tradução de W. H. Johnston e L. G. Struthers. London: George Allen \& Unwin, 1951, p.58.

${ }^{58}$ BONACCINI, Juan Adolfo. A Dialética em Kant e Hegel: Ensaio Sobre o Problema da Relação Entre Ser e Pensar. Natal: EdUFRN, 2000, p.169.
}

\begin{tabular}{|c|c|l|l|l|l|}
\hline intuitio & $\begin{array}{c}\text { ISSN } \\
1983-4012\end{array}$ & Porto Alegre & Vol.10 $-\mathrm{N}^{\circ} .1$ & $\begin{array}{l}\text { Julho } \\
2017\end{array}$ & p. 47-67 \\
\hline
\end{tabular}


aplicabilidade para esse princípio dentro do sistema lógico, de cunho eminentemente ontológico, proposto pelo filósofo alemão em tela.

\section{Conclusão}

Diante de todo o exposto, há de se concluir que Hegel se predispôs a ter um trabalho hercúleo ao tentar dar um novo enquadramento para a lógica, um ramo da filosofia que tinha passado por poucas mudanças desde o seu estabelecimento com Aristóteles ainda na idade antiga. Para alcançar o seu escopo, Hegel teve que trabalhar com um instrumental teórico totalmente novo e teve que remodelar alguns pontos de seus elementos lógicos para que pudesse promover a justificação da metafísica perante o ululante movimento cético de sua época. Desta maneira, a sua delimitação metodológica e o seu enfoque nos dois operadores lógicos básicos, o ser e o nada, foram fundamentais para o estabelecimento dessa forma conceitual e essencialista de se colocar a lógica sob uma perspectiva ontológica.

A compreensão mais bem aprofundada por Hegel acerca dos operadores lógicos e sua incidência temporal, e já amplamente debatida no desenvolvimento do trabalho em apreço, são as grandes novidades metafísicas por ele fornecidas. Esses elementos são um avanço sobre o terreno da análise transcendental fornecida anteriormente por Kant ao tratar posições metafísicas, e com a nova roupagem oferecida pelo instrumental hegeliano, há uma implemento valoroso no tratamento por ora ofertado. A abstração do ser e do nada fornecidos por Hegel estão de acordo com o seu projeto idealista, e, por causa dessa projeção intelectiva, agregam-se de maneira singular dentro do conjunto básico do seu pensamento, o qual enuncia as novas bases da modernidade, em suas definições científicas e espirituais que viriam a ser o cerne intelectual de seu tempo. Reverberando, assim, de maneira bastante pujante até os tempos hodiernos, em que ainda se discute como no artigo em tela, não apenas a relevância desses pressupostos metafísicos e ontológicos, bem como se debate a sua própria formulação bem como também a sua aplicabilidade nessa vertente específica do pensamento filosófico.

O significado de tal implementação para a época foi deveras impactante, de modo que o trabalho por ora empreendido apenas demonstrou uma faceta mínima da representação teórica do esquema dialético mostrado por Hegel. Na verdade, esse trabalho apenas apresentou uma fração mínima da primeira seção da Ciência da Lógica, sem ter o mínimo intento presunçoso de por acaso esgotar o tema ou conferir-lhe uma explanação definitiva e peremptória dos mais variados tópicos a serem explanados. No entanto, há de se destacar o esforço empreendido em esclarecer como se dá os movimentos circulares auto infligíveis de concatenação do ser, do nada e do devir. Tendo para isso que ter passado pelos delineamentos mais básicos do ser puro e as suas demonstrações abstratas fundantes desse novo ramo filosófico. Em síntese, espera-se ter alcançado o intento de dar um panorama geral da sistemática dialética

\begin{tabular}{|c|c|l|l|l|l|}
\hline intuitio & $\begin{array}{c}\text { ISSN } \\
1983-4012\end{array}$ & Porto Alegre & Vol.10- No.1 & $\begin{array}{l}\text { Julho } \\
2017\end{array}$ & p. $47-67$ \\
\hline
\end{tabular}


da lógica segundo Hegel, passando por alguns pontos específicos de turbulência na análise de alguns comentadores renomados do assunto proposto.

Há de se concluir, derradeiramente, que a unidade lógica do devir, segundo o pensamento unitário e de totalidade do projeto hegeliano é a pedra de toque do desenvolvimento científico do pensamento moderno. A busca pela realidade última e mais própria do ser humano é aquilo que a metafísica hegeliana almeja, sempre avançando sobre pontos de relevância outrora debatidos por seus predecessores, em específico Kant, que seria o seu grande debatedor direto em termos de pensamento e de disposição intelectual. Ademais, é de grande repercussão para o século seguinte (o século XX), a noção inicialmente posta por Hegel acerca do nada como um operador lógico, já que Heidegger posteriormente, ainda que não diretamente indique, debaterá a noção do aprofundamento do ser em retrospecto com o nada para pensar o próprio sentido do ser, a sua maior contribuição semântica no sentido de um alargamento dessa estrutura formal já pensada e de certa forma fornecida por parte de Hegel nas obras abordadas na confecção da presente exposição filosófica.

Definitivamente, é justamente a unidade lógica do pensamento, segundo retratado pelos esquemas sistemáticos hegelianos, que dá a possibilidade de o homem moderno ocupar seu espaço de destaque como ser racional de sua época.

\section{Referências}

ALBIZU, E. Hegel, Filósofo Del Presente. Buenos Aires: Almagesto, 2000.

BEISER, F. Hegel. New York: Routledge, 2005.

BONACCINI, Juan Adolfo. A Dialética em Kant e Hegel: Ensaio Sobre o Problema da Relação Entre Ser e Pensar. Natal: EdUFRN, 2000.

BRINKMANN, K. "The Dialetic of the Inverted World and The Meaning of Aufhebung". In: LIMNATIS, N. The Dimensions of Hegel's Dialectic. New York: Continuum, 2010. pp. 123-139.

BURBIDGE, J. W. The Logic of Hegel's Logic: An Introduction. Peterborough: Broadview Press, 2006.

BUTLER, C. Hegel's Logic: Between Dialectic and History. Chicago: Northwestern University Press, 1996.

DE VRIES, W. "Hegel's Logic and Philosophy of Mind". In: SOLOMON, Robert C.; HIGGINS, Kathleen M. (Org.). The age of German idealism. New York: Routledge, 2003. pp. 216-253.

FOSTER, M. N. Hegel's Idea of Phenomenology of Spirit. Chicago: The University of Chicago Press, 1998.

GALLAGHER, S. Hegel, History, and Interpretation. Albany: SUNY Press, 1997.

HARTNACK, J. An Introduction to Hegel's Logic. Tradução de Lars Ågård-Mogensen. Indianapolis: Hackett, 1998. HEGEL, G. W. F. Science of Logic. Tradução de W. H. Johnston e L. G. Struthers. London: George Allen \& Unwin, 1951.

HEIDEGGER, M. Ser e Tempo. Tradução de Márcia Sá Cavalcante Schuback. 3. ed. Rio de Janeiro: Vozes, 2008.

HOFFMAN, P. Doubt, Time, Violence. Chicago: The University of Chicago Press, 1989.

HOULGATE, S. The Opening of Hegel's Logic: From Being to Infinity. West Lafayette: Purdue University Press, 2006.

MARCUSE, H. Reason and Revolution: Hegel and The Rise of Social Theory. New York: Routledge, 1986.

SCHLITT, D. M. Hegel's Trinitarian Claim: A Critical Reflection. Leiden: E. J. Brill, 1984.

UCHIDA, H. Marx's Grundrisse and Hegel's Logic. New York: Routledge, 1988.

WARE, R. B. Hegel: The Logic of Self-Consciousness and The Legacy of Subjective Freedom. Edinburgh: Edinburgh University Press, 1999.

\begin{tabular}{|c|c|c|c|c|c|}
\hline intuitio & $\begin{array}{c}\text { ISSN } \\
1983-4012\end{array}$ & Porto Alegre & Vol.10 $-\mathrm{N}^{\circ} .1$ & $\begin{array}{l}\text { Julho } \\
2017\end{array}$ & p. 47-67 \\
\hline
\end{tabular}


Recebido em: 29/11/2016

Aprovado para a publicação em: 21/03/2017

\begin{tabular}{|c|c|c|c|c|c|}
\hline intuitio & $\begin{array}{c}\text { ISSN } \\
1983-4012\end{array}$ & Porto Alegre & Vol.10- No.1 & $\begin{array}{c}\text { Julho } \\
2017\end{array}$ & p. $47-67$ \\
\hline
\end{tabular}

